\title{
RACIAL/ETHNIC DIFFERENCES IN PREDICTORS OF PSA SCREENING IN A TRI-ETHNIC POPULATION
}

\author{
G. M. Monawar Hosain ${ }^{1}$, Maureen Sanderson², Xianglin L. Dư ${ }^{3}$, Wenyaw Chan 3 , Sara S. Strom ${ }^{4}$ \\ ${ }^{1}$ University of Texas Medical Branch at Galveston, Texas, USA \\ ${ }^{2}$ Meherry Medical School, Nashville, Tennessee, USA \\ ${ }^{3}$ School of Public Health, The University of Texas Health Science Center, Houston, Texas, USA \\ ${ }^{4}$ Department of Epidemiology, MD Anderson Cancer Center, The University of Texas, Houston, Texas, USA
}

\section{SUMMARY}

Background: This study was carried out to identify racial/ethnic differences in predictors of prostate-specific antigen (PSA) screening in a group of prostate cancer patients.

Methods: In this cross-sectional study, a total of 935 prostate cancer patients were recruited from the Texas Medical Center, Houston, between 1996 and 2004. It included 372 Caucasians, 346 African Americans and 217 Hispanics. A structured questionnaire was used to collect data on socio-demographic and life-style related variables, and self-reported PSA screening history through personal interview.

Results: African American (54.4\%) and Hispanic patients (42.3\%) were significantly less likely ( $p=0.004$ and $p<0.001$, respectively) to report having had PSA screening than Caucasian patients (63.2\%). Only annual check-up was found to be a significant predictor of PSA screening in Hispanics. Among Caucasians, education and annual check-up were significant predictors of PSA screening; whereas in African Americans, education, annual check-up, marital status and BMI were significant predictors of PSA screening.

Conclusions: The rates of PSA screening and its predictors varied by race/ethnicity in this tri-ethnic population. Health-education programs and culturally appropriate educational outreach efforts, especially targeted for high-risk groups, are needed to reduce these disparities.

Key words: PSA, screening, predictors, race, disparity

Address for correspondence: S. S. Strom, Department of Epidemiology, The University of Texas M.D. Anderson Cancer Center, 1155 Hermann Pressler Blvd., Unit 1340, Houston, TX 77030, USA. E-mail: sstrom@mdanderson.org

\section{INTRODUCTION}

Prostate cancer $(\mathrm{PCa})$ is the second leading cause of cancer death among US men. In 2010, it is expected that 217,730 US men will be diagnosed with $\mathrm{PCa}$ and that 32,050 men will die from this disease in the United States (1). Data have consistently shown racial/ethnic differences in PCa incidence and mortality in the United States. For example, African American men are more likely to be diagnosed at a younger age and are twice as likely to die from this disease as Caucasian men (2). Several studies have investigated the patterns and causes of these differences, without coming to a definitive conclusion $(2,3)$.

The prostate-specific antigen (PSA) test has become an important screening tool for PCa. However, there are some disagreements and controversies about its benefit; and thus, some groups have questioned its utility (4). In spite of its shortcomings, PSA testing has been well accepted in the general population as well as in common clinical practice. Though, its use as a screening tool has increased several-folds since the late 1980s, it has not increased uniformly across all racial/ethnic groups (5). At the community level, various factors such as cost, patients' perceptions, and access to health care as well as health literacy have an influence on the acceptance of screening programs (6). While several studies have shed some light on these differences, most studies were restricted to Caucasians and African Americans $(2,5,7)$.
Currently, Hispanics are the largest ethnic minority population in the United States; and thus, they should be included in all studies. There is also a need for PSA screening to be studied in different population and at various settings. Our study provided a special opportunity to examine the screening behaviour and experience of a group of PCa patients. It will help to identify the characteristics of a group of people that have or have not elected to have PSA screening. It may also provide some clues for long-term cancer outcome assessments and policy implications regarding PSA testing. To that end, the purposes of this study were to 1) examine the PSA screening rate, and, 2) identify demographic and lifestyle-related predictors of PSA screening by race/ethnicity in a group of PCa patients.

\section{MATERIALS AND METHODS}

\section{Study design:}

This study was a cross-sectional study based on an existing large PCa dataset at the M.D. Anderson Cancer Center (MDACC), Houston. The main purpose of the larger study was to collect epigenetic data on PCa.

\section{Study Population:}

Study subjects were patients aged 40 years and older with histologically confirmed primary adenocarcinoma of the prostate 
and were treated at tertiary care hospitals in the Texas Medical Center between 1996 and 2004.

\section{Data Collection}

Details of the data collection have previously been reported (8). Briefly, data were collected by using a structured questionnaire. The study was approved by the institutional review board (IRB) according to the guidelines of MDACC. All participants completed a 45- to 60-minute personal interview administered by a trained MDACC research interviewers. All interviews were conducted in either English or Spanish between January 1996 and January 2004.

The questionnaire requested information on race/ethnic background (self-reported), age at diagnosis, educational level, weight and height, marital status, family history of $\mathrm{PCa}$, annual physical check-up, smoking status, diabetes and PSA screening history. Patients were considered to have a positive family history of PCa if they reported having at least one affected first-degree relative with a PCa diagnosis. Patients were categorized as non-obese (body mass index $[\mathrm{BMI}]<30 \mathrm{~kg} / \mathrm{m}^{2}$ ) or obese $\left(\mathrm{BMI} \geq 30 \mathrm{~kg} / \mathrm{m}^{2}\right.$ ). Smokers were defined as individuals who had smoked more than 100 cigarettes in their lifetime.

The answer to the PSA screening question was considered as "Yes" if the patient had undergone a PSA test "exclusively" for screening purposes (with no clinical symptom) anytime in his life before PCa diagnosis. We operationalized it by excluding the last 1-year immediately before his PCa diagnosis. Keeping a 1-year window before the $\mathrm{PCa}$ diagnosis helped us to reduce the misclassification of PSA-related information. In this period, sometimes it is difficult for the patients to differentiate the PSA test for screening purposes from the PSA test for diagnostic or follow-up purpose. Since the data were collected from PCa patients, special attention was given to wording and phrasing of the questionnaire; and the research interviewers were trained specifically to capture the PSA screening information from PCa patients.

\section{Data Analysis}

Mean differences for continuous variables were tested using the t-test; whereas categorical variables were tested using Pearson's $\chi^{2}$ test. Crude odds ratios (ORs) and $95 \%$ confidence intervals (CIs) were calculated first to determine the association of various socio-demographic and lifestyle-related factors with the PSA screening test. Using univariate analysis, we included candidate variables with $\mathrm{p}<0.2$ in any race-specific analysis in multivariable models. A multivariable logistic-regression model was then run for each race/ethnic groups to measure the adjusted ORs. At this stage, a $p$ value of $<0.05$ was considered as significant. Statistical analysis was performed using STATA (STATA Corp LP, College Station, TX) software.

\section{RESULTS}

In total, 935 patients met the eligibility criteria for our study. It included 40\% Caucasians ( $\mathrm{n}=372), 37 \%$ African Americans $(\mathrm{n}=346)$ and $23 \%$ Hispanics $(\mathrm{n}=217)$ as shown in Table 1 . The mean age at diagnosis for African Americans (60.1 years) was significantly lower than that for Caucasians (62.0 years) and Hispanics (62.6 years). Caucasians were more likely to have a college education (82.3\%) and less likely to be diabetic (7.0\%). African Americans were more likely to be obese (38.7\%) and less likely to be married (73.7\%). Hispanics were more likely to be smokers $(71.4 \%)$ and less likely to have had annual physical check-up (58.5\%).

In our population, overall, $54.4 \%$ of patients $(n=509)$ reported ever having undergone PSA screening. Compared to Caucasians (63\%), African American patients were significantly less likely $(53 \%)$ to have had PSA screening $(\mathrm{p}<0.001)$; whereas Hispanics were less likely (42\%) than African American patients to have had PSA screening $(p=0.004)$. We also examined the PSA screening rates of $\mathrm{PCa}$ patients who were diagnosed at the T1c stage $(n=640)$, a stage when a patient with a positive PSA test is generally diagnosed, and it was found to be $64 \%$.

Crude odds ratios show that age at diagnosis, education, BMI, annual check-up and diabetes were associated with PSA screening (at $\mathrm{p}<0.2$ level) in Caucasian patients. Among African American patients, education, BMI, marital status, annual check-up and family history were associated with PSA screening $(\mathrm{p}<0.2)$; whereas in Hispanic patients, education, annual check-up and diabetes were associated with PSA screening $(\mathrm{p}<0.2)$.

In the multivariable logistic-regression model (Table 2), we included variables that were significant at $\mathrm{p}<0.2$ levels. In the multivariate logistic-regression model with simultaneous adjustment, only two factors, education $(\mathrm{OR}=1.97,95 \% \mathrm{CI}=1.12-3.48)$ and annual physical check-up $(\mathrm{OR}=1.97,95 \% \mathrm{CI}=1.12-3.48)$ appeared as significant predictors of PSA screening in Caucasians at $\mathrm{p}<0.05$ level.

In African Americans, education $(\mathrm{OR}=2.51,95 \% \mathrm{CI}=1.58$ 3.98), annual physical check-up $(\mathrm{OR}=2.93,95 \% \mathrm{CI}=1.68-5.11)$, obesity $(\mathrm{OR}=0.50,95 \% \mathrm{CI}=0.31-0.81)$ and being married $(\mathrm{OR}=1.69,95 \% \mathrm{CI}=1.01-2.85)$ were significant predictors of PSA screening $(\mathrm{p}<0.05)$. However, in Hispanics annual physical check-up was the only significant predictor of PSA screening $(\mathrm{OR}=3.44,95 \% \mathrm{CI}=1.86-6.38, \mathrm{p}<0.05)$.

\section{DISCUSSION}

In our study, just over half (54\%) of the PCa patients had reported having ever been screened for PSA testing. Results from the 2001 Behavioural Risk Factor Surveillance System data revealed that the proportion of men ever screened by PSA testing was $75 \%$ for people 50 years or older (9). In addition, other US studies done on other special groups like veterans, African Americans or older men showed that PSA screening ranged between $45 \%$ and $72 \%(10,11)$. Thus, our overall proportion $(54 \%)$ of ever 'PSA screening' falls at the lower end of this range. In addition, the PSA screening rate of those who were diagnosed at the T1c stage (64\%) in our study also falls in that range. Overall, we did not observe any higher prevalence of PSA screening among PCa cases than in the general population. The relatively lower proportion in our study could be due to the fact that many of our PCa patients were diagnosed in the early era of PSA screening tests (mid 1990s) when unwarranted fear and reluctance to undergo PSA screening was high, and poor knowledge about PSA screening was widespread, with seemingly lower access to preventive care $(12,13)$.

Our results revealed that African Americans and Hispanics are less likely to have had PSA screening than Caucasians. This 
Table 1. Sample characteristics by race/ethnicity

\begin{tabular}{|c|c|c|c|c|}
\hline Variables & $\begin{array}{c}\text { Caucasians } \\
(\mathrm{N}=372) \\
\mathrm{n}(\%)\end{array}$ & $\begin{array}{c}\text { African Americans } \\
\begin{array}{c}(\mathrm{N}=346) \\
\mathrm{n}(\%)\end{array}\end{array}$ & $\begin{array}{c}\text { Hispanics } \\
(\mathrm{N}=217) \\
\mathrm{n}(\%)\end{array}$ & $\begin{array}{c}\text { Group } \\
\text { difference }\end{array}$ \\
\hline \multicolumn{5}{|l|}{ Age at diagnosis } \\
\hline$\leq 65$ years & $152(40.9)$ & $184(53.2)$ & $87(40.1)$ & \multirow{3}{*}{$\mathrm{C}, \mathrm{H}>\mathrm{AA}$} \\
\hline$>65$ years & $220(59.1)$ & $162(46.8)$ & $130(59.9)$ & \\
\hline Mean \pm SD & $62.0 \pm 8.1$ & $60.1 \pm 8.9$ & $62.6 \pm 8.3$ & \\
\hline \multicolumn{5}{|l|}{ Education } \\
\hline$\leq 12$ years & $66(17.7)$ & $166(48.0)$ & $114(52.5)$ & \multirow{2}{*}{$\mathrm{C}>\mathrm{AA}, \mathrm{H}$} \\
\hline$>12$ years & $306(82.3)$ & $180(52.0)$ & $103(47.5)$ & \\
\hline \multicolumn{5}{|l|}{ BMI } \\
\hline Non obese $<30 \mathrm{~kg} / \mathrm{m}^{2}$ & $286(76.9)$ & $212(61.3)$ & $143(65.7)$ & \multirow{2}{*}{$\mathrm{AA}, \mathrm{H}>\mathrm{C}$} \\
\hline Obese $\geq 30 \mathrm{~kg} / \mathrm{m}^{2}$ & $86(23.1)$ & $134(38.7)$ & $74(34.3)$ & \\
\hline \multicolumn{5}{|l|}{ Marital status } \\
\hline Not married & $46(12.4)$ & $91(26.3)$ & $26(12.0)$ & \multirow{2}{*}{$\mathrm{C}, \mathrm{H}>\mathrm{AA}$} \\
\hline Married & $326(87.6)$ & $255(73.7)$ & $191(88.0)$ & \\
\hline \multicolumn{5}{|l|}{ Family history } \\
\hline Negative & $293(78.8)$ & $277(80.1)$ & $183(84.3)$ & \multirow{2}{*}{ NS } \\
\hline Positive & $79(21.2)$ & $69(19.9)$ & $34(15.7)$ & \\
\hline \multicolumn{5}{|l|}{ Have Annual check up } \\
\hline No & $94(25.3)$ & $81(23.4)$ & $90(41.8)$ & \multirow{2}{*}{$\mathrm{C}, \mathrm{AA}>\mathrm{H}$} \\
\hline Yes & $278(74.7)$ & $265(76.6)$ & $127(58.5)$ & \\
\hline \multicolumn{5}{|l|}{ Smoker } \\
\hline Never & $165(44.4)$ & $149(43.1)$ & $62(28.6)$ & \multirow{2}{*}{$\mathrm{H}>\mathrm{C}, \mathrm{AA}$} \\
\hline Current/former & $207(55.6)$ & $197(56.9)$ & $155(71.4)$ & \\
\hline \multicolumn{5}{|l|}{ Diabetes } \\
\hline No & $346(93.0)$ & $278(80.3)$ & $174(80.2)$ & \multirow{2}{*}{$\mathrm{AA}, \mathrm{H}>\mathrm{C}$} \\
\hline Yes & $26(7.0)$ & $68(19.7)$ & $43(19.8)$ & \\
\hline
\end{tabular}

* significant at $\mathrm{p}<0.05$ level; $\mathrm{BMI}=$ Body Mass Index; $\mathrm{C}=$ Caucasian, $\mathrm{AA}=\mathrm{African}$ American, $\mathrm{H}=$ Hispanics

replicates the findings of previous studies related to racial/ethnic differences $(5,14)$. It has been observed that men with a higher education are more knowledgeable about PSA screening and understand the importance of cancer prevention and early detection $(5,15,16)$. This study also revealed a strong positive association between having an annual check-up and PSA screening across all racial/ethnic groups, a finding supported by other studies too (17, 18). People with health insurance or a regular source of health care are more likely to report having had PSA screening. This finding suggests that suboptimal processes of care for patients with poor access represents a systemic problem for cancer screening in the United States $(19,20)$.

Among African Americans, in addition to education and annual check-up, two more additional factors, obesity and marital status, appeared to be strong predictors of PSA screening. In contrast to previous reports $(21,22)$, we found an inverse association between obesity and PSA screening. Researchers have observed that obese people seem to have poor self-esteem and that their poor selfconcept may be influenced by ethnicity $(23,24)$. Factors such as fear of disrespectful treatment, embarrassment at being weighed and unsolicited advice to lose weight may further increase their reluctance to undergo PSA screening (25). Our finding of lower rates of PSA screening among obese people is of concern, as barriers to early diagnosis of PCa in high-risk African American populations can adversely affect their long-term health outcomes.

Being married was found to be positively associated with PSA screening in African Americans, which corroborates previous findings $(6,26)$. It reflects that African American married men usually practice better general health-care behaviours than their unmarried counterparts. Nayeri et al. reported that married men tend to have a greater chance of early diagnosis of PCa because spouses usually encourage and persuade their partners to be screened at scheduled times, thus contributing to increased screening (26). Our findings do not support the notion that family history of $\mathrm{PCa}$ is a predictor of PSA screening. Studies have reported that men with a family history of PCa are more likely to undertake PSA screening because of greater perceived vulnerability of developing this disease (27). Further studies are warranted to examine this issue.

Among Hispanic men, having annual check-up was the only significant predictor of PSA screening. Compared with Caucasians 
Table 2. Predictors of Prostate Specific Antigen (PSA) screening test by race/ethnicity

\begin{tabular}{|c|c|c|c|}
\hline Variables & $\begin{array}{c}\text { Caucasians } \\
\text { Adjusted OR }(95 \% \mathrm{Cl})\end{array}$ & $\begin{array}{l}\text { African Americans } \\
\text { Adjusted OR (95\% Cl) }\end{array}$ & $\begin{array}{c}\text { Hispanics } \\
\text { Adjusted OR }(95 \% \mathrm{Cl})\end{array}$ \\
\hline \multicolumn{4}{|l|}{ Age at diagnosis } \\
\hline$\leq 60$ years & 1.00 & - & - \\
\hline$>60$ years & $1.53(0.97-2.41)$ & - & - \\
\hline \multicolumn{4}{|l|}{ Education } \\
\hline$\leq 12$ years & 1.00 & 1.00 & 1.00 \\
\hline$>12$ years & $2.02(1.15-3.56) \dagger$ & $2.44(1.55-3.83) \dagger$ & $1.74(0.98-3.12)$ \\
\hline \multicolumn{4}{|l|}{ BMI } \\
\hline Non obese $<30 \mathrm{~kg} / \mathrm{m}^{2}$ & 1.00 & 1.00 & - \\
\hline Obese $\geq 30 \mathrm{~kg} / \mathrm{m}^{2}$ & $0.63(0.38-1.05)$ & $0.48(0.30-0.77) \dagger$ & - \\
\hline \multicolumn{4}{|l|}{ Marital status } \\
\hline Non Married & - & 1.00 & - \\
\hline Married & - & $1.70(1.01-2.85) \dagger$ & - \\
\hline \multicolumn{4}{|l|}{ Family history } \\
\hline Negative & - & 1.00 & - \\
\hline Positive & - & $0.66(0.37-1.17)$ & - \\
\hline \multicolumn{4}{|l|}{ Have Annual check-up } \\
\hline No & 1.00 & 1.00 & 1.00 \\
\hline Yes & $2.04(1.23-3.90) \dagger$ & $2.90(1.67-5.04) \dagger$ & $3.49(1.90-6.41) \dagger$ \\
\hline \multicolumn{4}{|l|}{ Diabetes Mellitus } \\
\hline No & 1.00 & - & 1.00 \\
\hline Yes & $0.68(0.44-1.06)$ & - & $0.55(0.26-1.17)$ \\
\hline
\end{tabular}

3 (three) separate models were used for 3 racial/ethnic groups; †significant at $p<0.05$ level

and African Americans, annual check-up was more strongly associated with PSA screening in Hispanics. Fernandez-Esquer et al. showed that language and cultural barriers prevent Hispanics from establishing an appropriate link with health and preventivecare services, thus reducing their cancer screening rates (28).

This study has several limitations. The PSA screening information was based on self-report, and we could not compare it with the medical documents. Using a comparison group would have helped the interpretation of the results. The issue of selection bias was a concern in that these men were (presumably) much more likely to be screened than the average person. However, this study did not support that notion. Recall bias could be another issue, as those with higher-stage/grade prostate cancer may have recalled differentially. A 1-year lag period may not be sufficient to accurately differentiate a screening versus a diagnostic PSA test, and there remains a chance of misclassification. Another important limitation is that data collected from cancer patients and from tertiary care centers may not be as readily generalizable as data collected from the general population. To our knowledge, this study is the first investigation to focus on identifying the predictors of PSA screening among PCa patients, and these findings add new information to the literature by adding Hispanics as a separate group in the analysis.

It is a serious concern that a good number of PCa patients (46\%) never underwent PSA screening. Further investigation is needed to explore how stage of PCa diagnosis was related to the use of PSA testing by race. This study also revealed that the potential predictors of PSA screening in PCa patients vary by racial/ethnic groups. Thus, data derived from Caucasian and African American patients may inadequately identify at-risk Hispanic men. Further studies are warranted to verify this on recently diagnosed PCa patients as PSA-use guidelines have been streamlined in recent times. Our results highlight the importance of developing a more appropriate racially/ethnically sensitive program to address PSA screening disparities. It is important that men, especially from minority and less educated groups have easy access to PSA screening information, including benefits, risks and access to screening services.

\section{Acknowledgements}

This study was supported by grants NIH CA84964 and CA90270, and Department of Defense DAMD 17-98-1-8471.

\section{REFERENCES}

1. Jemal A, Siegel R, Xu J, Ward E. Cancer statistics, 2010. CA Cancer J Clin. 2010 Sep-Oct;60(5):277-300.

2. Robbins AS, Whittemore AS, Thom DH. Differences in socioeconomic status and survival among white and black men with prostate cancer. Am J Epidemiol. 2000 Feb 15;151(4):409-16. 
3. Powell IJ, Schwartz K, Hussain M. Removal of the financial barrier to health care: does it impact on prostate cancer at presentation and survival? A comparative study between black and white men in a Veterans Affairs system. Urology. 1995 Dec;46(6):825-30.

4. Harris R, Lohr KN. Screening for prostate cancer: an update of the evidence for the U.S. Preventive Services Task Force. Ann Intern Med. 2002 Dec 3;137(11):917-29.

5. Fowke JH, Schlundt D, Signorello LB, Ukoli FA, Blot WJ. Prostate cancor screening between low-income African-American and Caucasian men. Urol Oncol. 2005 Sep-Oct;23(5):333-40.

6. National Institutes of Health. Addressing health disparities: the NIH Program of Action [Internet]. [cited 2009 April 6]. Available from: http:// healthdisparities.nih.gov/whatare.html.

7. Gilligan T, Wang PS, Levin R, Kantoff PW, Avorn J. Racial differences in screening for prostate cancer in the elderly. Arch Intern Med. 2004 Sep 27;164(17):1858-64.

8. Spitz MR, Strom SS, Yamamura Y, Troncoso P, Babaian RJ, Scardino PT, et al. Epidemiologic determinants of clinically relevant prostate cancer. Int J Cancer. 2000 May 20;89(3):259-64.

9. Sirovich BE, Schwartz LM, Woloshin S. Screening men for prostate and colorectal cancer in the United States: does practice reflect the evidence? JAMA. 2003 Mar 19;289(11):1414-20.

10. Steele CB, Miller DS, Maylahn C, Uhler RJ, Baker CT. Knowledge, attitudes, and screening practices among older men regarding prostate cancer. Am J Public Health. 2000 Oct;90(10):1595-600.

11. Weinrich SP. Prostate cancer screening in high-risk men: African American Hereditary Prostate Cancer Study Network. Cancer. 2006 Feb 15;106(4):796-803

12. Wolf AM, Nasser JF, Wolf AM, Schorling JB. The impact of informed consent on patient interest in prostate-specific antigen screening. Arch Intern Med. 1996 Jun 24;156(12):1333-6.

13. Chan EC, Haynes MC, O'Donnell FT, Bachino C, Vernon SW. Cultura sensitivity and informed decision making about prostate cancer screening. J Community Health. 2003 Dec;28(6):393-405.

14. Lu-Yao G, Stukel TA, Yao SL. Prostate-specific antigen screening in elderly men. J Natl Cancer Inst. 2003 Dec 3;95(23):1792-7.

15. Eisen SA, Waterman B, Skinner CS, Scherrer JF, Romeis JC, Bucholz K, et al. Sociodemographic and health status characteristics with prostate cancer screening in a national cohort of middle-aged male veterans. Urology. 1999 Mar;53(3):516-22.
16. Steenland K, Rodriguez C, Mondul A, Calle EE, Thun M. Prostate cancer incidence and survival in relation to education (United States). Cancer Cause Control. 2004 Nov;15(9):939-45.

17. Finney Rutten LJ, Meissner HI, Breen N, Vernon SW, Rimer BK. Factors associated with men's use of prostate-specific antigen screening: evidence from Health Information National Trends Survey. Prev Med. 2005 Apr;40(4):461-8.

18. Moran WP, Cohen SJ, Preisser JS, Wofford JL, Shelton BJ, McClatchey MW. Factors influencing use of the prostate-specific antigen screening test in primary care. Am J Manag Care. 2000 Mar;6(3):315-24.

19. Breen N, Wagener DK, Brown ML, Davis WW, Ballard-Barbash R. Progress in cancer screening over a decade: results of cancer screening from the 1987, 1992, and 1998 National Health Interview Surveys. J Natl Cancer Inst. 2001 Nov 21;93(22):1704-13.

20. Scales CD Jr, Antonelli J, Curtis LH, Schulman KA, Moul JW. Prostatespecific antigen screening among young men in the United States. Cancer. 2008 Sep 15;113(6):1315-23.

21. Fowke JH, Signorello LB, Underwood W 3rd, Ukoli FA, Blot WJ. Obesity and prostate cancer screening among African-American and Caucasian men. Prostate. 2006 Sep 15;66(13):1371-80.

22. Scales CD Jr, Curtis LH, Norris RD, Schulman KA, Dahm P, Moul JW. Relationship between body mass index and prostate cancer screening in the United States. J Urol. 2007 Feb;177(2):493-8.

23. Wadden TA, Stunkard AJ. Social and psychological consequences of obesity. Ann Intern Med. 1985 Dec;103(6 ( Pt 2)):1062-7.

24. Allan JD, Mayo K, Michel Y. Body size values of white and black women Res Nurs Health. 1993 Oct;16(5):323-33.

25. Amy NK, Aalborg A, Lyons P, Keranen L. Barriers to routine gynecological cancer screening for White and African-American obese women. Int J Obes (Lond). 2006 Jan;30(1):147-55

26. Nayeri K, Pitaro G, Feldman JG. Marital status and stage at diagnosis in cancer. N Y State J Med. 1992 Jan;92(1):8-11.

27. Bratt O. Hereditary prostate cancer: clinical aspects. J Urol. 2002 Sep;168(3):906-13.

28. Fernández-Esquer ME, Espinoza P, RamirezAG, McAlister AL. Repeated Pap smear screening among Mexican-American women. Health Educ Res. 2003 Aug;18(4):477-87. 